\title{
Erratum to: Impact of domain size on the simulation of Indian summer monsoon in RegCM4 using mixed convection scheme and driven by HadGEM2
}

\author{
S. K. Dash • K. C. Pattnayak · S. K. Panda • \\ Deepika Vaddi $\cdot$ Ashu Mamgain
}

Published online: 3 February 2015

(C) Springer-Verlag Berlin Heidelberg 2015

\section{Erratum to: Clim Dyn}

DOI 10.1007/s00382-014-2420-1

The original version of the article has been published with a sub title 'Impact of domain size on ISM simulations' printed just below the main title. It should be removed from the title page of the article. Further, the running head in the right hand pages should read as 'Impact of domain size on ISM simulations' instead of 'mixed convection scheme and driven by HadGEM2'.

The online version of the original article can be found under doi:10.1007/s00382-014-2420-1.

S. K. Dash · K. C. Pattnayak $(\varangle) \cdot$ S. K. Panda $\cdot$ D. Vaddi ·

A. Mamgain

Centre for Atmospheric Sciences, Indian Institute of Technology

Delhi, Hauz Khas, New Delhi 110 016, India

e-mail:kcpattnayak@gmail.com 